\title{
SNPs in genes implicated in radiation response are associated with radiotoxicity and evoke roles as predictive and prognostic biomarkers
}

\author{
Ghazi Alsbeih ${ }^{1,4^{*}}$, Medhat El-Sebaie ${ }^{2}$, Najla Al-Harbi', Khaled Al-Hadyan' ${ }^{1}$, Mohamed Shoukri
}

\section{Abstract}

Background: Biomarkers are needed to individualize cancer radiation treatment. Therefore, we, have investigated the association between various risk factors, including single nucleotide polymorphisms (SNPs) in candidate genes and late complications to radiotherapy in our nasopharyngeal cancer patients.

Methods: A cohort of 155 patients was included. Normal tissue fibrosis was scored using RTOG/EORTC grading system. A total of 45 SNPs in 11 candidate genes (ATM, XRCC1, XRCC3, XRCC4, XRCC5, PRKDC, LIG4, TP53, HDM2, CDKN1A, TGFB1) were genotyped by direct genomic DNA sequencing. Patients with severe fibrosis (cases, G3-4, $n=48)$ were compared to controls $(\mathrm{GO}-2, n=107)$.

Results: Univariate analysis showed significant association $(P<0.05)$ with radiation complications for 6 SNPs (ATM G/A rs1801516, HDM2 promoter T/G rs2279744 and T/A rs1196333, XRCC1 G/A rs25487, XRCC5 T/C rs1051677 and TGFB1 C/T rs1800469). In addition, Kaplan-Meier analyses have also highlighted significant association between genotypes and length of patients' follow-up after radiptherapy. Multivariate logistic regression has further sustained these results suggesting predictive and prognostic roles of SNPS.

Conclusions: Univariate and multivariate analysis suggest that radiation toxicity in radiotherapy patients are associated with certain SNPs, in genes including HDM2 promoter studied for the 1st time. These results support the use of SNPs as genetic predictive markers for clinicał radiosensitivity and evoke a prognostic role for length of patients' follow-up after radiotherapy

Keywords: Single nucleotide polymorphism/SNP), Radiosensitivity, Late reactions to radiotherapy, Fibrosis, Follow up, Nasopharyngeal carcinoma

\section{Background}

Genetic variations are frequent in humans, and the challenge of radiogenomic stydies is to determine which polymorphisms influence individual radiosensitivity and the risk to develop severe complications following radiotherapy [1]. Single nucleotide polymorphism (SNP) is the largest type of inherited genetic variation [2]. These polymorphic variations can influence the stability of mRNA, rate of transcription, the protein translation

* Correspondence: galsbeih@kfshrc.edu.sa

${ }^{1}$ Radiation Biology Section, Biomedical Physics Department, King Faisal Specialist Hospital and Research Centre, P.O. Box 3354, Riyadh 11211 ,

Saudi Arabia

${ }^{4}$ Radiation Biology Section, Biomedical Physics Department, KFSHRC, MBC-03, P.O. Box 3354, Riyadh 11211, Saudi Arabia

Full list of author information is available at the end of the article and/or the protein-protein interactions leading to suboptimum function and expression of different degrees of clinical radiation sensitivity [3]. To identify these variations, many investigators followed an intuitive approach of targeting SNPs in candidate genes arbitrarily involved in radiation response [4-6]. Although many studies, carried out often on limited number of RT patients, have reported significant associations, results were globally inconsistent between studies [7].

The pathways involved in radiation response encompass multitude of genes of which we have selected 11 candidate genes for their presumed or demonstrated influence on radiosensitivity [3,7-9]. These include CDKN1A (p21), TP53, ATM, HDM2, TGFB1, XRCC1, XRCC3, XRCC4, $X R C C 5$ (Ku80), PRKDC, and LIG4 which are involved in 
various pathways. Since SNPs in these genes are likely to affect the outcome to radiation treatment [1], in this study we have genotyped 45 (12 primary and 33 neighboring) SNPs in 155 Head and Neck cancer patients treated with curative radiotherapy, and have been associated with follow-up and the grade of fibrosis in normal tissues.

\section{Methods}

\section{Patients' population and clinical data}

A total of 155 Head and Neck cancer patients had consented to be enrolled in this study during treatment or regular follow-up of their disease. The patients were treated by standardized 3D conformal RT, before the implementation of IMRT, for nasopharyngeal carcinoma as described elsewhere $[10,11]$. Total radiation dose to the upper neck was $66 \mathrm{~Gy}$. Where possible, patients $(n=47)$ received a boost of 2 additional fractions to the nasopharynx to bring the dose received to $70 \mathrm{~Gy}$. Locally advanced stages (II to IVB, $n=74$ ) received neoadjuvant and concurrent chemotherapy consisting of cisplatinum and epirubicin [10]. The grade (G) of subcutaneous and deep tissue fibrosis, a late radiation-induced complication, was jointly evaluated by two participating physicians according to the RTOG/EORTC grading system. The maximum grade of fibrosis recorded over the length of the patients' follow-up has been reported. For groups comparison, patients with major toxicity [12], severe fibrosis $(G 3-4)$, were referred to as the radiosensitive group (eases, $n=48$ ) and were compared to patients with minor (G0-2) fibrotic reactions (controls, $n=107$ ). The KFSHRC Research Ethics Committee has approved the study (RAC \# 2000 031 and 2040 025) and all patients had signed informed consent.

\section{DNA extraction, amplification, sequencing and} genotyping of polymorphisms

During the regular follow-up of the patients, a $5 \mathrm{ml}$ blood sample was drawn from consenting patients. DNA was extracted using Puregene DNA Purification Kit (Gentra System, USA) according to the manufacturer's instruction. The sefected 12 primary SNPs were: CDKN1A ( $p 21$, Cip1) codon 31 C/A /Ser/Arg) rs1801270, TP53 (p53) codon $72 \mathrm{G} / \mathrm{C}$ (Arg/Pro) rs1042522, HDM2 (MDM2) promoter position 309 rs2279744, ATM codon 1853 G/A (Asp/Asn) rs1801516, XRCC1 codon 399 G/A (Arg/Gln) rs25487, XRCC3 codon $241 \mathrm{C} / \mathrm{T}$ (Thr/Met) rs861539, XRCC4 codon 247 G/T (Ala/Ser) rs3734091, XRCC5 (Ku80) 3' UTR A/G rs1051685, LIG4 (DNA Ligase IV) codon 591 A/G (Ile/Val) rs2232641, LIG4 codon $9 \mathrm{C} / \mathrm{T}$ (Thr/lle) rs1805388, PRKDC (DNA-PKCs) codon 3434 A/G (Ile/ Thr) rs7830743, TGFB1 (TGFß1) codon $10 \mathrm{C} / \mathrm{T}$ (Leu/Pro) rs1982073. The PCR primers used are available upon request. Relevant segments of DNA were amplified by thermal cycling, sequenced using the DYEnamic ET Dye Terminator Cycle Sequencing Kit (Amersham Biosciences) and genotyped using SeqManII sequence analysis software (DNASTAR Inc.).

\section{Data analysis}

The univariate analysis of the association between SNPS allelic frequencies and grade of fibrosis were measured by the odds ratio (OR) with its $95 \%$ confidence interval. Significance of OR was assessed by the Chi-square $\left(x^{2}\right)$ test, continuity uncorrected. A $P$-value of $0.0,5$ or less is considered statistically significant. Kaplan-Meier analysis was used to evaluate the potential relationship between genotypes and length of patients follow-up. Multivariate logistic regression was used to assess the joint effect of all potential risk factors. Statistical analysis was carried out using the IBM SPSS Statistics platform (Version 19, SPSS Science, IL, USA).

\section{Results}

\section{Patients and treatment}

The age of patients at RT ranged between 15 and 77 years/old with a median of 47 . There were 39 females and 116 males. All patients had completed at least 24 months of follow-up after RT (range: 24-180 months, median: 40 months). Late normal tissue reactions to radiotherapy (xerostomia, skin atrophy and subcutaneous and deep tissue fibrosis) were scored, however, only grade of fibrosis is reported here because it was completed for all patients. There were $17,54,36,38$, and 10 patients who had exhibited fibrotic reactions of grade 0 , $1,2,3$ and 4, respectively.

Patients with major toxicity (G3 and G4, cases) were compared to those having minor reactions (G0, G1 and G2, controls) [12]. Therefore, radiosensitive patients with severe subcutaneous and/or deep tissue fibrosis (G3-4, cases, $\mathrm{n}=48$ ) were compared to patients having no, mild or moderate fibrosis (G0-2, controls, $\mathrm{n}=107$ ). The distribution of controls and radiosensitive patients according to chemotherapy and radiation boost received is given in Figure 1. Briefly, patients who received chemotherapy (79) and RT boost (54) were proportionally distributed between controls and cases. Thus, the ratio of patients who received chemotherapy to the patients who did not, were comparable in the control and the radiosensitive groups $(0.50$ vs. $0.52, P=0.80)$. Similarly, the average total doses received (with and without boost) in controls (67.50 Gy, SD = 1.94) and in the radiosensitive groups $(67.17 \mathrm{~Gy}, \mathrm{SD}=1.84)$ were not significantly different $(P=0.35)$. Associated diseases were uncommon ( 25 patients) who were proportionally distributed between cases and controls. 


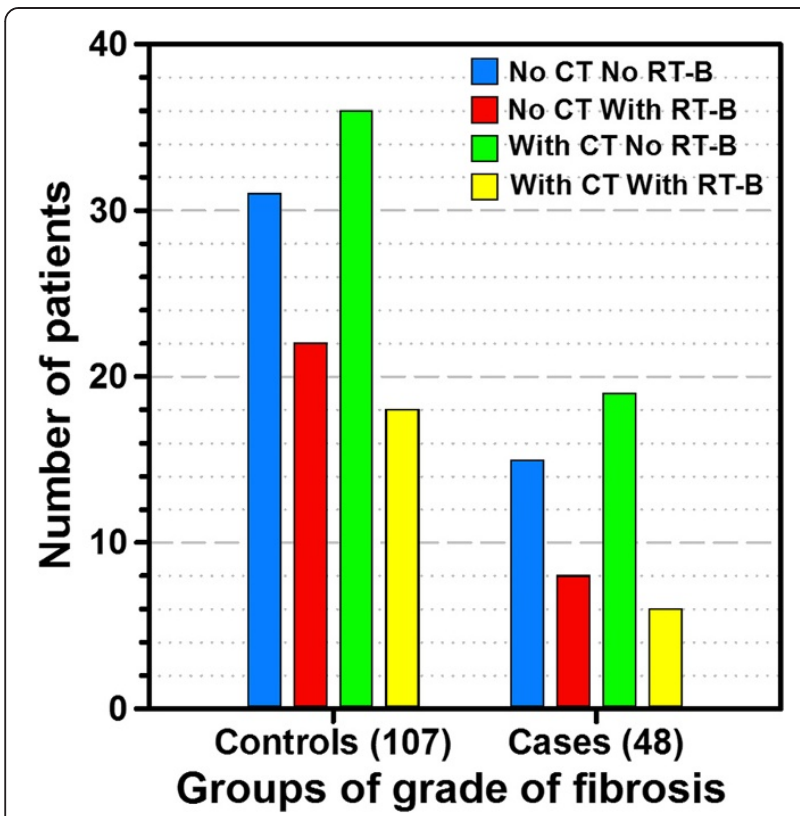

Figure 1 Distribution of the 155 nasopharyngeal carcinoma patients according to the grade of subcutaneous and deep tissue fibrosis following radiotherapy. The patients developed either minimal to moderate (controls: G0-2) or severe (cases: G3-4) fibrotic reactions. Patients who received chemotherapy (CT) or radiotherapy boost (RT-B) are indicated.

\section{Genotyping analysis}

Between the 45 SNPs genotyped, 16 were all majority (wild-types) alleles that have been omitted from the analysis. There were wide variations in the distribution of the different genotypes according to the grade of fibrosis. The allelic frequencies are given in Table 1. As compared to the controls $(\mathrm{G} 0-2)$, the radiosensitive group (G3-4) harbored relatively higher number of variant ATM rs1801516 A allele which appeared to be a risk factor $(\mathrm{OR}=2.86$ CI 95\%: 1.18-6.48, $P<0.01)$, and lower numbers of the variants $H D M 2$ rs 2279744 G $(\mathrm{OR}=0.49$, CI 95\%: 0.29-0.84, $P<0.01)$, the rare HDM2 rs1196333 A (OR = 0.13, CI 95\%: 0,02-0.99, $P=0.02)$, TGFB1 rs1800469 $\mathrm{T}(\mathrm{OR}=0.57, \mathrm{CI} 95 \%: 0.34-0.96, P=0.03), X R C C 1 \mathrm{rs} 25487$ $A(\mathrm{OR}=0.41$, Cl 95\%: 0.21-0.79, $P<0.01)$, and XRCC5 rs1051677 C (OR = 0.39, CI 95\%: 0.17-0.91, $P=0.02$ ) alleles which appeared to have protective effect; therefore, the majority alleles were the risk factors. In addition, we have computed the False Discovery Rate (FDR) for all P-values of the SNPs tested. The FDR-values of the 6 significant SNPs were between 0.14 and 0.009 . This indicates that the expected proportion of false positive discovery satisfies the significance threshold allowed for this test $(<0.20)$.

The relationship between the genotypes of the 6 significantly-associated-SNPs and the length of followup following RT, a surrogate measure of patients' survival assuming that most absence to follow-up are due to death, was evaluated using Kaplan-Meier analysis (Figure 2). Results showed significant difference in the median follow-up with respect to genotypes for ATM rs1801516, HDM2 rs2279744 and XRCC1 rs25487 (Log Rank Mantel-Cox test: $P=0.001,0.03$ and 0.04 , respectively). For these SNPs, the protective genotype, whether majority or minority allele, correspond to longer patients' follow-up. Thus, the estimated medians followup in months were: $A T M$ rs1801516 $\mathrm{A} / \mathrm{A}=24, \mathrm{~A} / \mathrm{G}=80$, $\mathrm{G} / \mathrm{G}=114 ; H D M 2 \mathrm{rs} 2279744 \mathrm{~T} / \mathrm{T}=75, \mathrm{~T} / \mathrm{G}=140, \mathrm{G} / \mathrm{G}=$ 114; XRCC1 rs25487 G/G = 79, G/A = 112, $\mathrm{A} / \mathrm{A}=180$.

The joint effect of all pøtential risk factors (age, gender, total radiation dose, chemotherapy, follow-up, associated disease and genotypes), was assessed using multivariate logistic regression (Table 2). Results showed that HDM2 rs2279744, HDM2 rs1196333, TGFB1 rs1800469, XRCC1 rs25487 and Follow-Up $(P=0.03$, $0.03,0.007,0.002$ and 0.007 , respectively) were significantly associated with the group of fibrotic reaction (G0-2 versus G3-4))

\section{Discussion}

The aim of this study was to evaluate in our local cancer patients whether various risk factors including genetic polymorphic variations in candidate genes involved in radiation response are associated with the severity of RT-induced fibrotic reactions in normal tissues. The 155 Head and Neck cancer patients included in this report had nasopharyngeal carcinoma. This cancer site is prevalent in Saudi Arabia and is ideal for this type of study because patients follow standardized treatment with curative radiation without surgery [10]. This could be considered contribution to the radiogenomic consortium that contains mainly breast, prostate and gynecologic cancer patients [13].

Among the 45 genetic variations scored, univariate analysis showed significant association between grade of fibrosis and allelic frequency of 6 SNPs (ATM rs1801516, HDM2 rs2279744, HDM2 rs1196333, TGFB1 rs1800469, XRCC1 rs25487 and XRCC5 rs1051677; Table 1) and therefore, could be considered candidate for predictive markers testing. These results were further sustained as the values of the False Discovery Rate (FDR) of these SNPs $(0.14-0.009)$ have satisfied the significance threshold allowed for this test $(<0.20)$. Interestingly, apart from $A T M$ where the variant $A$ allele was associated with increased risk, the variant alleles of the remaining significantly associated SNPs showed decreased risk (Odds or Risk Ratios $<1$ ) to develop severe fibrosis, and therefore, they exhibit protective effect.

In addition, Kaplan-Meier analysis on these 6 SNPs suggested that the protective alleles of 3 of these SNPs (ATM rs1801516 A, HDM2 rs2279744 G, and XRCC1 
Table 1 Allele frequencies of the assessed polymorphisms in 155 Head and Neck cancer patients who either developed minimal (controls: G0-2) or severe (cases: G3-4) late reactions (fibrosis) after radiotherapy

\begin{tabular}{|c|c|c|c|c|c|c|}
\hline \multirow[t]{3}{*}{ Gene and SNP } & \multicolumn{2}{|c|}{ Allele $1^{a}$} & \multicolumn{2}{|c|}{ Allele $2^{b}$} & \multirow{3}{*}{$\begin{array}{l}\text { Odds ratio } \\
(95 \% \mathrm{Cl})\end{array}$} & \multirow[t]{3}{*}{ P-value } \\
\hline & Cases & Controls & Cases & Controls & & \\
\hline & n (\%) & n (\%) & n (\%) & n (\%) & & \\
\hline CDKN1A C/A rs1801270 & $74(77)$ & $157(73)$ & $22(23)$ & $57(27)$ & $0.82(0.47-1.44)$ & 49 \\
\hline TP53 G/C rs1042522 & $52(54)$ & $112(52)$ & $44(46)$ & $102(48)$ & $0.93(0.57-1.51)$ & 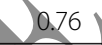 \\
\hline TP53 C/T rs1800371 & $96(100)$ & $213(99.5)$ & $0(0)$ & $1(0.5)$ & NI & \\
\hline ATM G/A rs1801516 & $82(85)$ & $202(94)$ & $14(15)$ & $12(6)$ & $2.86(1.18-6.48)$ & $<0.01$ \\
\hline HDM2 T/G rs2279744 & $71(74)$ & $125(58)$ & $25(26)$ & $89(42)$ & $0.49(0.29-0.84)$ & $<0.01$ \\
\hline HDM2 T/A rs1196333 & $95(99)$ & $198(93)$ & $1(1)$ & $16(7)$ & $0.13(0.02-0.99)$ & 0.02 \\
\hline TGFB1 G/A rs9282871 & $95(99)$ & $213(99.5)$ & $1(1)$ & $1(0.5)$ & NL & NI \\
\hline TGFB1 C/T rs1982073 & $40(42)$ & $102(48)$ & $56(58)$ & $112(52)$ & 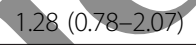 & 0.32 \\
\hline TGFB1 G/C rs1800471 & $92(96)$ & $207(97)$ & $4(4)$ & $7(3)$ & & $\mathrm{NI}$ \\
\hline TGFB1 C/T rs1800469 & $67(70)$ & $122(57)$ & $29(30)$ & $92(43)$ & $(0.34-0.96)$ & 0.03 \\
\hline TGFB1 G/A rs11466314 & $96(100)$ & $213(99.5)$ & $0(0)$ & & $\mathrm{NI}$ & NI \\
\hline TGFB1 del rs8179182 & $94(98)$ & $214(100)$ & $2(2)$ & & $\mathrm{NI}$ & NI \\
\hline TGFB1 C/T rs1800472 & $92(96)$ & $199(93)$ & $4(4)$ & 1 & $0.58(0.19-1.79)$ & 0.33 \\
\hline TGFB1 C/T rs11466334 & $95(99)$ & $213(99.5)$ & $1(1)$ & $1(0.5)$ & $\mathrm{Nl}$ & $\mathrm{NI}$ \\
\hline XRCC1 G/A rs 25487 & $83(86)$ & $155(72)$ & $13(14)$ & 28) & $0.41(0.21-0.79)$ & $<0.01$ \\
\hline XRCC1 C/T rs3213368 & $87(91)$ & $193(90)$ & $9(9)$ & $21(10)$ & $0.95(0.42-2.16)$ & 0.90 \\
\hline XRCC1 G/A rs2139720 & $88(92)$ & $190(89)$ & & $24(11)$ & $0.72(0.31-1.67)$ & 0.44 \\
\hline XRCC1 C/T rs3213369 & $96(100)$ & $213(99.5)$ & & $1(0.5)$ & NI & NI \\
\hline XRCC3 G/A rs861539 & $55(57)$ & $133(62)$ & & $81(38)$ & $1.22(0.75-1.99)$ & 0.42 \\
\hline XRCC3 A/C rs3212112 & $95(99)$ & $213(99.5)$ & 7) & $1(0.5)$ & $\mathrm{NI}$ & NI \\
\hline XRCC4 G/T rs3734091 & $95(99)$ & 213 (99.5) & (1) & $1(0.5)$ & $\mathrm{NI}$ & NI \\
\hline XRCC5 A/G rs41296835 & $96(100)$ & $213(99.5)$ & $0(0)$ & $1(0.5)$ & $\mathrm{NI}$ & $\mathrm{NI}$ \\
\hline XRCC5 T/C rs1051677 & $89(93)$ & & $7(7)$ & $36(17)$ & $0.39(0.17-0.91)$ & 0.02 \\
\hline XRCC5 A/G rs 1051685 & $85(89)$ & $195(91)$ & $11(11)$ & $19(9)$ & $1.33(0.61-2.91)$ & 0.48 \\
\hline PRKDC T/C rs7830743 & $93(97)$ & $197(92)$ & $3(3)$ & $17(8)$ & $0.37(0.11-1.31)$ & 0.11 \\
\hline LIG4 T/C rs1805384 & $90(94)$ & $200(93)$ & $6(6)$ & $14(7)$ & $0.95(0.36-2.56)$ & 0.92 \\
\hline LIG4 C/T rs4987182 & $93(97)$ & $209(98)$ & $3(3)$ & $5(2)$ & $\mathrm{Nl}$ & $\mathrm{NI}$ \\
\hline L/G4 C/T rs1805389 & (1) & $206(96)$ & $1(1)$ & $8(4)$ & $\mathrm{Nl}$ & $\mathrm{NI}$ \\
\hline LIG4 C/T rs1805388 & $91(95)$ & $195(91)$ & $5(5)$ & $19(9)$ & $0.56(0.20-1.56)$ & 0.26 \\
\hline
\end{tabular}

Significantly associated SNPs, are highlighted in bold.

a Allele 1: majority or wild-type allele. " Allele 2: minority or variant allele. NI: Not Informative because of low frequency.

rs25487 A) significantly correlate with longer follow-up of patients. Our results suggest that on average, the presence of protective allele at the heterozygous status would increase patients' follow-up by 51 months while homozygous status would increase this index by 77 months. Thus, these SNPs could be used as prognostic biomarkers for length of follow-up following radiotherapy, as patients harboring protective alleles have higher probability to live longer (Figure 2). Estimated median follow-up suggests that harboring one protective allele of each of these SNPs would increase survival by about 4 years, while having the 2 nd protective allele would add 2 more years.
Multivariate logistic regression, that assesses the joint effect of various risk factors, has confirmed the association between HDM2 T/G rs2279744, HDM2 T/A rs1196333, TGFB1 C/T rs1800469, XRCC1 G/A rs25487, follow-up and radiosensitivity (Table 2 ). These are interesting results that plaid in favor of the potential use of genetic markers as predictors of normal tissue response and prognostic of follow-up. This is an important conclusion since the subject is currently a hot topic debate [7]. For instance, a large prospective study has failed to replicate previously reported associations between individual SNP genotype and radiation toxicity [7]. On the contrary, genome-wide associations study evaluating erectile dysfunction 

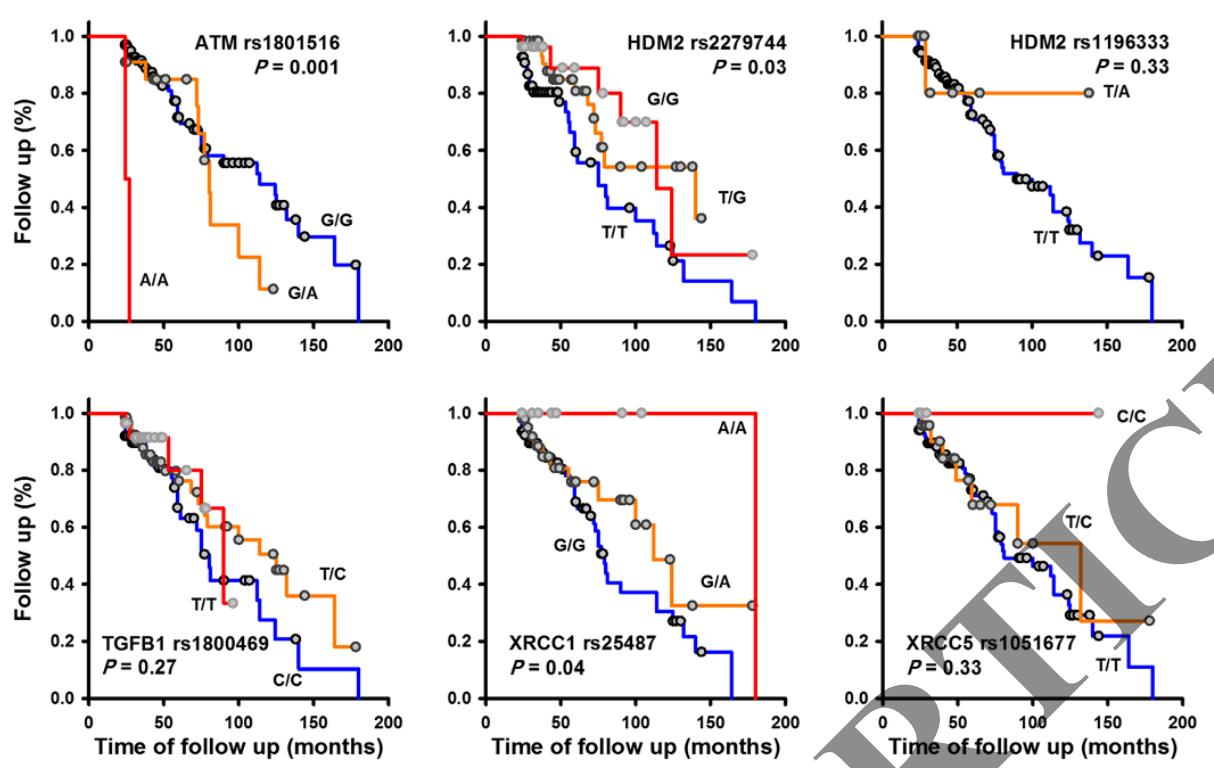

Figure 2 Kaplan-Meier analysis of the relationship between the genotypes of the 6 significantly-associated-SNPs and length of patients' follow-up following radiotherapy. Symbols represent censored data points.

following radiotherapy has showed significant association not only in a gene that plays a role in male gonad function, but also in genes that relate to specific African ancestry [14].

This is the first study on the association between $H D M 2$ T309G promoter (rs2279744) and radiosensitivity; previous studies were only concerned with its cancer predisposing potential [15]. The functional polymorphic variant in the HDM2 promoter at position 309 (rs2279744) have been suggested to affect the transcriptional activator) SP1 binding, thereby modulating HDM2 transcription level. The $G$ variant has been shown to increase the affinity for $\mathrm{Sp} 1$, resulting in higher levels of HDM2 mRNA and protein

Table 2 Multivariate logistic regression analysis of various risk factors that might affect patients' risk to develop severe fibrosis following radiotherapy

\begin{tabular}{lc}
\hline Risk factors & $\boldsymbol{P}$ value \\
\hline ATM G/A rs1801516 & 0.55 \\
\hline HDM2 T/G rs2279744) & $\mathbf{0 . 0 3}$ \\
\hline HDM2 T/A rs1196333 & $\mathbf{0 . 0 3}$ \\
\hline TGFB1 C/Trs1800469 & $<\mathbf{0 . 0 1}$ \\
\hline XRCC1 G/A rs25487 & $<\mathbf{0 . 0 1}$ \\
\hline XRCC5 (Ku80) T/C rs1051677 & 0.42 \\
\hline Gender & 0.79 \\
\hline Age at Radiotherapy & 0.56 \\
\hline Total Radiation Dose & 0.39 \\
\hline Chemotherapy & 0.21 \\
\hline Follow Up & $<\mathbf{0 . 0 1}$ \\
\hline Associated Diseases & 0.48 \\
\hline
\end{tabular}

Significant associations are highlighted in bold. and the subsequent attenuation of the TP53 pathway [16]. Results presented here showed that the same variant $G$ allele, and also the variant $G$ allele in the neighboring HDM 2 rs2279744 SNP, is associated with reduced risk to develop late normal tissues complications, a phenomenon that is dependent on the amount of cell depletion following radiotherapy. Therefore, in line with our results, it is conceivable that this HDM2 G variant allele could promote cell survival following irradiation and thus, cells would appear more radioresistant, despite the probable high risk of genomic instability due to presumably attenuated TP53. This may also have implication for the promotion of secondary cancers following radiotherapy.

In addition, this is also the 1st study to report association between XRCC5 (KU80) polymorphisms and clinical radiosensitivity. XRCC5 is a component of the non-homologous end-joining (NHEJ) to repair DNA double-strand breaks. Previously, SNPs in XRCC5 have been shown to influence cancer risk and chromosomal radiosensitivity [15]. Our study showed that, although uncommon, the variant XRCC5 rs1051677 $C$ allele was more frequent in the controls, thus it has a protective effect. The variant ATM rs1801516 A allele (Asn) was previously reported to be significantly associated with increased radiation sensitivity [17]. Other studies have also showed similar association with enhanced risk of various adverse reactions after RT [18]. On the other hand, the majority XRCC1 rs25487 allele (Arg) was associated with increased risk to develop late reactions to radiotherapy (Reviewed in [19]). This suggests that the variant (or minority) allele could confer higher radioresistance in favor of normal tissues involved in the 
radiation treatment [5]. TGFB1 encodes for the versatile cytokine TGFB1 assumed to be involved in response to tissue injuries. Therefore, SNPs that alter protein production can results in excessive deposition of scar tissue and fibrosis. Therefore, many SNPs have been studied in the literature and the effect of haplotype needs to be clarified as co-segregation of polymorphic variations in TGFB1 gene has been suggested to play a role in radiation response $[3,5,20]$.

Results presented here are encouraging and illustrates that radiation response requires the concerted action of multiple genes and, therefore, it is a complex genetically controlled trait with the outcome being determined by multitude of additive effects. In addition, the original demonstration of an association between certain SNPs and length of followup after radiotherapy suggests prognostic role for patients' survival. The results also indicate that not all variant SNPs are risky, and some of them could be advantageous from a radiosensitivity point of view. The SNPs studied were synonymous, nonsynonymous and in non-coding regions of the genome. From an evolutionary perspective, the genome is in consistent development due to environmental interactions and, in general, natural selection favors the allele of the SNP that constitutes the most advantageous genetic adaptation. It is possible that the substitutions observed frequently are likely to be neutral or favorable, whereas those observed rarely are likely to be deleterious [21]. Although a large prospective study has failed to replicate previously reported associations between individual SNPs genotype and radiation toxicity [7], a genome-wide associations study evaluating erectile dysfunction following radiotherapy for prostate cancer has showed significant association not only in a gene that plays a role in male gonad development and function, but also in genes that relate to specific African ancestry that would not have been identified in a cohort of European ancestry [14]. The genomic revolution with the advent of highthroughput techniques can help uncovering the panoply of these interacting factors at the DNA (genome), RNA (transcriptome) or protein (proteome) level. Research using genome-wide analysis tools heralds the future of individualized radiation treatment in broadly personalized medicine. In addition to predictive and prognostic testing, the products of the identified genes could become tárgets for innovative therapies in susceptible individuals.

\section{Conclusions}

Univariate analysis showed that between 45 SNPs in 11 genes involved in cell cycle control and DNA repair, 6 were significantly associated with radiation toxicity in radiotherapy patients. Kaplan-Maier analysis has highlighted a significant association between genotype and follow-up of patients. Multivariate logistic analysis has sustained these conclusions. Larger cohort, independent replication of these findings and genome wide association studies (GWAS) are required to confirm these results and validates the use of SNPs as predictive and prognostic biomarkers to individualize radiotherapy on genetic basis.

\section{Competing interests}

We declare no competing interest.

Authors' contributions
GA designed the study, analyzed results and drafted manuscript. NAH and $\mathrm{KAH}$ processed and genotyped samples. MES and NAR collected samples and followed patients. MS performed statistical analysis. All authors read and approved the final manuscript.

\section{Acknowledgments}

We wish to thank Dr. B. Meyer Mr. M. Rajab for helping in DNA sequencing, Ms. M. Al-Buhairi, L. A. Venturina S. Al-Qahtani and N. Venturina for technical help and Dr. B. Moftah for continuous support. Funded by KFSHRC grant 2000031 and 2040 025

\section{Author details}

${ }_{1}^{1}$ Radiation Biology Section, Biomedical Physics Department, King Faisal Specialist Hospital and Research Centre, P.O. Box 3354, Riyadh 11211, Saudi Arabia. 2Radiation Oncology Section, Oncology Centre, King Faisal Specialist Hospital and Research Centre, P.O. Box 3354, Riyadh 11211, Saudi Arabia. ${ }^{3}$ National Biotechnology Center, King Faisal Specialist Hospital and Research Centre, P.O. Box 3354, Riyadh 11211, Saudi Arabia. ${ }^{4}$ Radiation Biology Section, Biomedical Physics Department, KFSHRC, MBC-03, P.O. Box 354, Riyadh 11211, Saudi Arabia.

Received: 2 February 2013 Accepted: 14 May 2013

Published: 22 May 2013

\section{References}

1. Parliament MB: Radiogenomics: associations in all the wrong places? Lancet Oncol 2012, 13:7-8.

2. Cargill M, Altshuler D, Ireland J, Sklar P, Ardlie K, Patil N, Shaw N, Lane CR, Lim EP, Kalyanaraman N, et al: Characterization of single-nucleotide polymorphisms in coding regions of human genes. Nat Genet 1999, 22:231-238

3. Andreassen CN, Alsner J, Overgaard M, Overgaard J: Prediction of normal tissue radiosensitivity from polymorphisms in candidate genes. Radiother Oncol 2003, 69:127-135.

4. Andreassen CN, Alsner J, Overgaard M, Sorensen FB, Overgaard J: Risk of radiation-induced subcutaneous fibrosis in relation to single nucleotide polymorphisms in TGFB1, SOD2, XRCC1, XRCC3, APEX and ATM-a study based on DNA from formalin fixed paraffin embedded tissue samples. Int J Radiat Biol 2006, 82:577-586.

5. Alsbeih G, Al-Harbi N, Al-Hadyan K, El-Sebaie M, Al-Rajhi N: Association between normal tissue complications after radiotherapy and polymorphic variations in TGFB1 and XRCC1 genes. Radiat Res 2010, 173:505-511.

6. Talbot CJ, Tanteles GA, Barnett GC, Burnet NG, Chang-Claude J, Coles CE, Davidson S, Dunning AM, Mills J, Murray RJ, et al: A replicated association between polymorphisms near TNFalpha and risk for adverse reactions to radiotherapy. Br J Cancer 2012, 107:748-753.

7. Barnett GC, Coles CE, Elliott RM, Baynes C, Luccarini C, Conroy D, Wilkinson JS, Tyrer J, Misra V, Platte R, et al: Independent validation of genes and polymorphisms reported to be associated with radiation toxicity: a prospective analysis study. Lancet Oncol 2012, 13:65-77.

8. Chang-Claude J, Popanda O, Tan XL, Kropp S, Helmbold I, von Fournier D, Haase W, Sautter-Bihl ML, Wenz F, Schmezer P, Ambrosone CB: Association between polymorphisms in the DNA repair genes, XRCC1, APE1, and XPD and acute side effects of radiotherapy in breast cancer patients. Clin Cancer Res 2005, 11:4802-4809.

9. West CM, Elliott RM, Burnet NG: The genomics revolution and radiotherapy. Clin Oncol (R Coll Radiol) 2007, 19:470-480. 
10. Al-Amro A, Al-Rajhi N, Khafaga Y, Memon M, Al-Hebshi A, El-Enbabi A, ElHusseiny G, Radawi A, Belal A, Allam A, El-Sebaie M: Neoadjuvant chemotherapy followed by concurrent chemo-radiation therapy in locally advanced nasopharyngeal carcinoma. Int I Radiat Oncol Biol Phys 2005, 62:508-513.

11. Alsbeih GA, Al-Harbi NM, El-Sebaie MM, Al-Rajhi NM, Al-Hadyan KS, AbuAmero KK: Involvement of mitochondrial DNA sequence variations and respiratory activity in late complications following radiotherapy. Clin Cancer Res 2009, 15:7352-7360.

12. Cox DJ, Stetz J, Pajak FT: Toxicity criteria of the Radiation Therapy Oncology Group (RTOG) and the European Organization for Research and Treatment of Cancer (EORTC). Int J Radiat Oncol Biol Phys 1995, 31:1341-1346.

13. West C, Rosenstein BS, Alsner J, Azria D, Barnett G, Begg A, Bentzen S, Burnet N, Chang-Claude J, Chuang E, et al: Establishment of a radiogenomics consortium. Int J Radiat Oncol Biol Phys 2010, 76:1295-1296.

14. Kerns SL, Ostrer H, Stock R, Li W, Moore J, Pearlman A, Campbell C, Shao Y, Stone N, Kusnetz L, Rosenstein BS: Genome-wide association study to identify single nucleotide polymorphisms (SNPs) associated with the development of erectile dysfunction in African-American men after radiotherapy for prostate cancer. Int I Radiat Oncol Biol Phys 2010, 78:1292-1300.

15. Al-Hadyan KS, Al-Harbi NM, Al-Qahtani SS, Alsbeih GA: Involvement of single-nucleotide polymorphisms in predisposition to head and neck cancer in Saudi Arabia. Genet Test Mol Biomarkers 2012, 16:95-101.

16. Bond GL, Hu W, Bond EE, Robins H, Lutzker SG, Arva NC, Bargonetti J, Bartel F, Taubert H, Wuerl P, et al: A single nucleotide polymorphism in the MDM2 promoter attenuates the p53 tumor suppressor pathway and accelerates tumor formation in humans. Cell 2004, 119:591-602.

17. Alsbeih G, El-Sebaie M, Al-Harbi N, Al-Buhairi M, Al-Hadyan K, Al-Rajhi N: Radiosensitivity of human fibroblasts is associated with amino acid substitution variants in susceptible genes and correlates with the number of risk alleles. Int I Radiat Oncol Biol Phys 2007, 68:229-235.

18. Andreassen CN, Overgaard J, Alsner J, Overgaard M, Herskind C, Cesaretti JA, Atencio DP, Green S, Formenti SC, Stock RG, Rosenstein BS: ATM sequence) variants and risk of radiation-induced subcutaneous fibrosis after postmastectomy radiotherapy. Int I Radiat Oncol Biol Phys 2006, 64:776

19. Andreassen $\mathrm{CN}$ : Can risk of radiotherapy-induced normal tissue complications be predicted from genetic profiles? Acta Oncol 2005, 44:801-815

20. Azria D, Ozsahin M, Kramar A, Peters S, Atencio DP, Crompton NE, Mornex F, Pelegrin A, Dubois JB, Mirimanoff RO, Rosenstein BS: Single nucleotide polymorphisms, apoptosis, and the development of severe late adverse effects after radiotherapy. Clin Cancer Res 2008, 14:6284-6288.

21. Zhu Y, Spitz MR, Amos Cl, Lin J, Schabath MB, Wu X: An evolutionary perspective on single-nucleotide polymorphism screening in molecular cancer epidemiology. Cancer Res 2004, 64:2251-2257.

doi:10.1186/1748-717X-8-125

Cite this article as: Alsbein et al: SNPs in genes implicated in radiation response are associated with radiotoxicity and evoke roles as predictive and prognostic bromarkers. Radiatjon Oncology 2013 8:125.

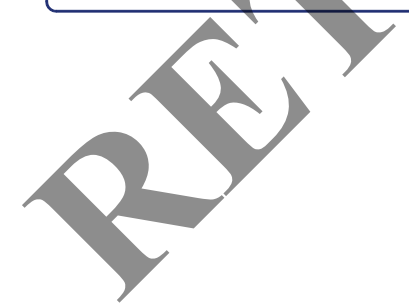

\section{Submit your next manuscript to BioMed Central and take full advantage of:}

- Convenient online submission

- Thorough peer review

- No space constraints or color figure charges

- Immediate publication on acceptance

- Inclusion in PubMed, CAS, Scopus and Google Scholar

- Research which is freely available for redistribution 